\title{
Sociodemographic and Clinical Characteristics of Persons Presenting with Deliberate Self-harm to the Accident and Emergency Department of the University Hospital of the West Indies
}

\author{
M Henry ${ }^{1}$, P Whitehorne-Smith², WD Abel ${ }^{2}$
}

\begin{abstract}
Objective: The primary objective of this study was to determine the sociodemographic and clinical characteristics of all persons who presented to the Accident and Emergency Department of the University Hospital of the West Indies with a history of deliberate harm over a six-month period.

Methods: The dockets of patients presenting with deliberate self-harm were collected and reviewed for the information. A questionnaire was designed to extract the information. Data were analysed using SPSS version 17 and RXC programme.

Results: Of the total number of dockets reviewed $(n=61)$, $78 \%$ of patients were below age 40 years, with a mean age of 28 years. Sixty-four per cent were female, $82 \%$ were single, $83 \%$ lived with someone, $80 \%$ had a secondary school level of education and $72 \%$ were unemployed. Overdose of medications was the main method of harm. Seventy-five per cent of patients did not use illicit substances. There was a significant association found between reason for self-harm and psychiatric illness $(\mathrm{p}<0.001)$.

Conclusion: Given these preliminary results, it would be useful to conduct a wider, island-wide study to determine the extent of self-harming behaviour in Jamaica so that appropriate interventions can be implemented to reduce this problem.
\end{abstract}

Keywords: Deliberate self-harm, clinical characteristics

WIMJ Open 2015; 2 (1): 28

\section{INTRODUCTION}

Deliberate self-harm is a complex and perplexing behaviour that has been explored in the scientific community for many years without definitive results. Extant research evidence indicates that the frequency of deliberate self-harm has increased in recent years (1-3).

Deliberate self-harm can be considered as an acute, non-fatal act of self-harm carried out deliberately in the form of an acute episode by an individual with variable motivation. The aim to end life may have been variable or absent. This phenomenon is also referred to as attempted suicide or parasuicide. Deliberate self-harm is a violent act that persons commit against themselves which may result in levels of morbidity or even death. The lethality of the methods used may help to determine the end result, that is, cutting, overdosing on medications, self-poisoning, or use of weapons [eg guns] (4).

Numerous studies have noted that the sociodemographic factors associated with deliberate self-harm include

From: ${ }^{1}$ South East Regional Health Authority, Ministry of Health and ${ }^{2}$ Department of Community Health and Psychiatry, The University of the West Indies, Kingston 7, Jamaica, West Indies.

Correspondence: Professor W Abel, Department of Community Health and Psychiatry, Section of Psychiatry, The University of the West Indies, Kingston 7, Jamaica, West Indies. E-mail: drwendelabel@gmail.com age, gender, marital status and employment status. Available figures, both relative to population size and in absolute numbers, show that non-fatal suicidal behaviour is more prevalent among younger people than older people. The ratio of fatal to non-fatal suicidal behaviour in those over age 65 years is usually estimated to be of the order of 1:2-3, while in young people under 25 years, the ratio may reach as high as 1:100 $200(5,6)$. Although suicidal behaviour is less frequent in the elderly, the probability of a fatal outcome is much higher (7, 8).

Also, as a general trend, the rates of non-fatal suicidal behaviour tend to be two to three times higher in women than in men. In most countries, men commit more suicide and women make more suicide attempts: this is called the gender paradox (9). There are some exceptions, like China, where women commit more suicide than men, and a few places such as India, Singapore, Hong Kong, Kuwait and Japan where the suicidal behaviour has almost the same figures between both genders (9).

Studies on the relationship between marital status and suicide reveal high rates of suicide among single or nevermarried people in western cultures, even higher rates among widowed people, and some of the highest rates among people who are separated or divorced $(10,11)$. Interestingly, marriage is not protective in all cultures. Higher rates of both fatal and non-fatal suicidal behaviour have been reported among 
married women in Pakistan, compared with both married men and single women $(12,13)$.

It has been suggested by the literature that the level of education of persons may impact on whether or not they practise self-harming behaviour. However, the literature has been conflicting, as some studies suggest that educational level may not be a significant risk factor (14).

In terms of clinical features, existing literature has pointed out that both depression and anxiety are commonly seen in persons who engage in deliberate self-harm, but anxiety/tension has been found to maintain a substantial unique relationship to deliberate self-harm over depression (3).

Some of the principal psychiatric and psychological factors associated with suicide are major depression, other mood (affective) disorders, such as bipolar disorder (a condition characterized by periods of depression, alternating with periods of elevated mood or mania, and in which the changed states can last for days or even months), schizophrenia, anxiety and disorders of conduct and personality, impulsivity and a sense of hopelessness (15-22). There is an associated risk of suicide in patients who have been diagnosed with a psychiatric disorder. An estimate of $25 \%$ to $50 \%$ of all patients with bipolar disorder will make a suicide attempt (23). Mood disorders, substance use disorders and their co-morbidity increase the risk of suicide attempts (24), with many of the substance use disorders having an underlying depression.

Given what has been uncovered about deliberate selfharm internationally, it becomes crucial to examine and determine the sociodemographic and clinical characteristics of persons presenting with deliberate self-harm within the Jamaican context.

\section{SUBJECTS AND METHOD}

This was a retrospective descriptive study consisting of a review of dockets of all patients who presented with deliberate self-harm including attempted suicide and parasuicide to the Accident and Emergency Department of the University Hospital of the West Indies (UHWI), over the period March to September 2011.

A total sample of 61 dockets met the criteria for deliberate self-harm as outlined for this study. A data extraction form was utilized to elicit sociodemographic and clinical features of these patients. This form captured information related to age, gender, marital status, educational status, employment status and employment group, living arrangement, substance history, method of harm, reason for selfharm, presence or absence of past psychiatric history, past psychiatric diagnosis, provisional psychiatric diagnosis, follow-up, mode of therapy and services referred.

The information was obtained from the clinical histories and diagnoses that were taken by the duty psychiatric resident and approved by the consultant psychiatrist on duty at the time the patient was being seen. All diagnoses were based on the Diagnostic and Statistical Manual of Mental Disorders, fourth edition, text revision (DSM-IVTR).

The data obtained were analysed using the statistical programmes SPSS for Windows, version 17, and the RXC (R by C) programme created by Mark Miller. Frequencies and a comparison of means using the Mann Whitney U test were done with SPSS programme, while exact tests were performed using the RXC programme.

\section{RESULTS}

Sixty-one patient records were reviewed over the six-month period. More patient records were initially listed for review, but were not located.

\section{Sociodemographic characteristics}

The majority of patients were female $(63.9 \%)$ and roughly $49 \%$ of them were below the age of 20 years. The mean age was 28 years with a range of 11 to 65 years. Table 1 also shows that $82 \%$ of the population examined was single, while approximately $10 \%$ of the population examined was married. The remainder were in common-law unions, visiting relationship, or divorced.

Of note, no one in the sample had less than a secondary level of education (Table 1). However, the majority of the population examined, $72.1 \%$, was unemployed, of which approximately $36 \%$ were students. Other employment groups included entertainers, security and labourers.

Table 1: Sociodemographic characteristics of patients

\begin{tabular}{lcc}
\hline Description & $\boldsymbol{f}$ & $\mathbf{\%}$ \\
\hline Gender & 22 & 36.1 \\
Male & 39 & 63.9 \\
Female & & \\
Age group (years) & 30 & 49.2 \\
$<19$ & 24 & 39.3 \\
$20-39$ & 7 & 11.5 \\
$>40$ & & \\
Marital status & 50 & 82 \\
Single & 6 & 9.8 \\
Married & 2 & 3.3 \\
Common-law & 1 & 1.6 \\
Visiting & 2 & 3.3 \\
Divorced & & \\
Educational level & 49 & 80.3 \\
Secondary & 11 & 18 \\
Tertiary & 1 & 1.6 \\
Vocational & & \\
\hline
\end{tabular}

\section{Clinical characteristics}

The most frequent method of self-harm included overdosing on pills (33\%), followed by hanging (23\%) and cutting [14\%] (Table 2). Among those who overdosed on medication, approximately $11 \%$ of them took analgesics, while approximately $8 \%$ of them used antibiotics. Approximately $7 \%$ of the study population used a combination of medications: analgesics and vitamins, analgesics and antihypertensive, and analgesics and antibiotics. 
Table 2: Clinical characteristics of patients

\begin{tabular}{lcc}
\hline Description & $\boldsymbol{f}$ & $\boldsymbol{\%}$ \\
\hline Method of self-harm & & \\
Overdose of pills & 20 & 33 \\
Hanging & 14 & 23 \\
Ingestion of poison & 5 & 8.2 \\
Cutting self & 9 & 14.8 \\
Other & 13 & 21 \\
Reasons for self-harm & & \\
Hearing voices & 11 & 18 \\
Interpersonal conflict & 29 & 47.5 \\
Feeling sad & 14 & 23 \\
Other & 7 & 11.5 \\
Substance history & & \\
Cigarettes & 2 & 3.3 \\
Alcohol & 5 & 8.2 \\
Cannabis & 2 & 3.3 \\
Crack/cocaine & 1 & 1.6 \\
Combination & 5 & 8.2 \\
None & 46 & 75.4 \\
Past psychiatric history & & \\
Yes & 15 & 24.6 \\
No & 46 & 75.4 \\
Past psychiatric diagnosis & & \\
Schizophrenia and brief psychotic & & \\
disorder & 4 & 6.6 \\
Mood disorders & 6 & 9.8 \\
Other & 5 & 8.2 \\
None & 46 & 75.4 \\
\hline
\end{tabular}

Approximately $48 \%$ of the population examined had interpersonal conflicts as their reason for harming themselves while $23 \%$ reported that they were feeling sad, and $18 \%$ reported that they were hearing voices commanding them to harm themselves (Table 2). Other reasons that were given included a panic attack, financial constraints and witnessing a violent event.

The majority of the population presented with symptoms of feeling sad (59\%), while approximately $20 \%$ reported that they were feeling upset and $16 \%$ of the population reported hearing voices. Other presenting symptoms noted included mumbling and 'chatting foolishness', which is saying statements that were incoherent to the listener.

Most of the patients reported that they did not use substance (75.4\%); also, most did not have a past psychiatric history (75.4\%). However, for those who did report a past psychiatric history, mood disorders were most commonly reported $(9.8 \%)$, followed by 'other' $(8.2 \%)$.

\section{DISCUSSION}

The study results indicated that $63.9 \%$ of females reported deliberate self-harm. These data are consistent with the literature which indicates that globally, females report greater rates of self-harm than males, while males tend to be engaged in behaviour that would result in more successful suicides (25).
The majority of persons who committed self-harm were below the age of 40 years. This finding is inconsistent with international findings which indicate that self-harm rises with increasing age. There were exceptions to this finding in a few countries, such as Australia, Canada, United Kingdom, and Guyana (25). Jamaica seems to align with these exceptions.

It was noted that $85 \%$ of the patients were not involved in a relationship ( $82 \%$ were single and $3 \%$ were divorced) while approximately $15 \%$ were in committed relationships. This supports findings from previous research that persons who are not involved in a committed relationship are at greater risk of committing self-harming behaviour, as relationships are noted to be protective factors $(10,11)$. For those persons who were married $(10 \%)$ and committed deliberate self-harm, this may be explained by some other factor affecting the relationship at that time.

Consistent with the literature is the finding in this study that males reported greater use of lethal methods than females (26). More males used hanging, while more females used medications, and the medication of choice was analgesics. The fact that analgesics were the most common type of medication used is in keeping with global findings $(27,28)$. These medications are readily available over-thecounter in supermarkets, pharmacies, and several shops across the island. Acetaminophen is the most commonly used over-the-counter analgesic and antipyretic in many countries, including Canada, and it has emerged as the leading cause of deliberate self-poisoning.

Importantly, the present findings diverged from those of previous studies which noted substance use as a significant reason for deliberate self-harm. The majority of patients who presented to the Accident and Emergency Department did not report using substances to their attending physician. The reasons related to this divergence needs to be explored in future studies.

The major reason for self-harm given by this group of patients was interpersonal conflicts. This is significant, and may suggest that there are some basic relationship issues that may need to be addressed at these ages. Approximately 50\% of the 61 patients were below the age of 19 years. Any interpersonal conflicts may have been due to poor relationships with their caregivers, that is, their parents, relatives or guardians. A study conducted in 2003 by Pottinger et al suggests this as a risk factor for suicidal behaviour in children and adolescents (29). With respect to the adults who reported interpersonal conflicts as their reason for self-harm, poor coping skills may also play a part in the self-harming behaviour that they presented with.

Furthermore, of the patients examined $(n=61)$, approximately $72 \%$ were unemployed. Studies suggest that persons who are unemployed are at greater risk of committing deliberate self-harm due to financial stress which unemployment may generate (30-32). This may suggest that 
unemployment in this group of persons examined is a significant factor contributing to their self-harming behaviour.

This study suggests that there is a significant association between past psychiatric illness and self-harming behaviour. Those that had a history of past psychiatric illness were found to have multiple incidents of self-harming behaviour. This is in keeping with findings of researchers who argue that co-morbid psychiatric illnesses are associated with repeated self-harming behaviour and persons with a past history of a psychiatric illness are more likely to repeat the self-harming behaviour $(8,14,22,23)$.

Some limitations of the study include the small sample size as well as the fact that data were taken from a hospital pool which may not represent a true picture of self-harm that may be occurring in the general population. Other shortfalls include the duration of time to obtain the sample, missing dockets and the inability to confirm patients' actual diagnoses. In addition, the study was a retrospective analysis and is associated with uncontrolled confounding factors.

\section{CONCLUSION}

Notwithstanding the limitations, these preliminary findings can help to increase the understanding of self-harm behaviour in our population and how it relates to what has been found globally. Moreover, the findings indicate the need for a broader study which captures persons throughout the island. As a profile of those who present with these behaviours is developed, clinicians may be better able to assess, treat and recommend approach management for patients presenting with these concerns.

\section{REFERENCES}

1. Cleaver K. Characteristics and trends of self-harming behavior in young people. Br J Nurs 2007; 16: 148-52.

2. Gratz K. Measurement of deliberate self-harm: preliminary data on the deliberate self-harm inventory. J Psychopathol Behav Assess 2001; 23: 253-63.

3. Klonsky ED, Oltmanns T, Turkheimer E. Deliberate self-harm in a nonclinical population: prevalence and psychological correlates. Am J Psychiatry 2003; 160: 1501-8.

4. Mustafa Soomro G. Deliberate self-harm (and attempted suicide). Clin Evid (Online) 2008; 2008: 1012.

5. McIntire MS, Angle CR. The taxonomy of suicide and self-poisoning: a pediatric perspective. In: Wells CF, Stuart IR, eds. Self-destructive behavior in children and adolescents. New York, NY: Van Nostrand Reinhold; 1981: 224-49.

6. McIntosh JL, Santos JF, Hubbard RW, Overholser JC. Elder suicide: research, theory and treatment. Washington, DC: American Psychological Association; 1994.

7. De Leo D, Diekstra RFW. Depression and suicide in late life. Toronto and Bern: Hogrefe/Huber; 1990.

8. De Leo D, Padoani W, Scocco P, Lie D, Bille-Brahe U, Arensman E et al. Attempted and completed suicide in older subjects: results from the WHO/EURO Multicentre Study of Suicidal Behaviour. Int J Geriatr Psychiatry 2001; 16: 300-10.
9. Canetto SS, Sakinofsky I. The gender paradox in suicide. Suicide Life Threat Behav 1998; 28: 1-23.

10. Kposowa AJ. Marital status and suicide in the National Longitudinal Mortality Study. J Epidemiol Community Health 2000; 54: 254-61.

11. Smith JC, Mercy JA, Conn JM. Marital status and the risk of suicide. Am J Public Health 1998; 78: 78-80.

12. Khan MM, Reza H. Gender differences in nonfatal suicidal behaviour in Pakistan: significance of sociocultural factors. Suicide Life Threat Behav 1998; 28: 62-8.

13. Khan MM, Reza H. The pattern of suicide in Pakistan. Crisis 2000; 21: 31-5.

14. Mekonnen D, Kebede Y. The prevalence of suicide ideation and attempts among individuals attending an adult psychiatry outpatient clinic in Gondar, Ethiopia. Afr Health Sci 2011; 11: 103-7.

15. World Health Organization. Primary prevention of mental, neurological and psychosocial disorders. Geneva: World Health Organization; 1998.

16. Blumenthal SJ. Suicide: a guide to risk factors, assessment, and treatment of suicidal patients. Med Clin North Am 1988; 72: 937-71.

17. Beck AT, Brown G, Berchick RJ, Stewart BL, Steer RA. The relationship between hopelessness and ultimate suicide: a replication with psychiatric outpatients. Am J Psychiatry 1990; 147: 190-5.

18. Guze SB, Robins E. Suicide and primary affective disorders. Br J Psychiatry 1970; 117: 437-8.

19. Harris EC, Barraclough B. Suicide as an outcome for mental disorders. Br J Psychiatry 1997; 170: 447-52.

20. Botswick JM, Pankratz VS. Affective disorders and suicide risk: a reexamination. Am J Psychiatry 2000; 157: 1925-32.

21. Roy A. Suicide in schizophrenia. In: Roy A, ed. Suicide. Baltimore, MD: Williams and Wilkins; 1986: 97-112.

22. Caldwell CB, Gottesman II. Schizophrenics kill themselves too: a review of risk factors for suicide. Schizophr Bull 1990; 16: 571-89.

23. Rucci P, Frank E, Kostelnik B, Fagliolini A, Mallinger AG, Swartz HA et al. Suicide attempts in patients with bipolar I disorder during acute and maintenance phases of intense treatment with pharmacotherapy and adjunctive therapy. Am J Psychiatry 2002; 159: 1160-4.

24. Aharanovich E, Liu X, Nunes E, Hasin DS. Suicide attempts in substance abusers: effects of major depression in relation to substance use disorders. Am J Psychiatry 2002; 159: 1600-2.

25. Canetto SS, Sakinofsky I. The gender paradox in suicide. Suicide Life Threat Behav 1998; 28: 1-23.

26. Stefanello S, Cais C F, Mauro ML, Freitas GV, Botega NJ. Gender differences in suicide attempts: preliminary results of the multisite intervention study on suicidal behavior (SUPRE-MISS) from Campinas, Brazil. Rev Bras Psiquiatr 2008; 30: 139-43. Epub 2007 Dec 20.

27. Prior MJ, Cooper K, Cummins P, Bowen D. Acetaminophen availability increases in Canada with no increase in the incidence of reports of inpatient hospitalizations with acetaminophen overdose and acute liver toxicity. Am J Ther 2004; 11: 443-52.

28. Rumack BH. Acetaminophen hepatotoxicity: the first 35 years. J Toxicol Clin Toxicol 2002; 40: 3-20.

29. Pottinger AM, Milbourn P, Leiba JW. Suicidal behaviour and risk factors in children and adolescents in Jamaica. West Indian Med J 2003; 52: 127-30.

30. Platt S. Unemployment and suicidal behaviour: a review of the literature. Soc Sci Med 1984; 19: 93-115.

31. Yip PSF. Suicides in Hong Kong. Soc Psychiatry Psychiatr Epidemiol 1997; 32: 243-50.

32. Morrell S, Taylor R, Quine S Kerr C. Suicide and unemployment in Australia 1907-1990. Soc Sci Med 1993; 36: 749-56. 
Submitted 13 Oct 2014

Accepted 27 Oct 2014

Published 16 Mar 2015

Online: http://www.mona.uwi.edu/wimjopen/article/1629

(C) Henry et al 2015

This is an open access article made freely available under Creative Commons Attribution 4.0 International (CC BY 4.0). Users are free to share, copy and adapt this work as long as the copyright holder (author) is appropriately and correctly credited. See http:// creativecommons.org/licences/by/4.0/deed.en_us for more information. 